\title{
PROPRIEDADES MECÂNICAS DO CONCRETO ADICIONADO COM BORRACHA DE PNEUS
}

\section{MECHANICAL PROPERTIES OF TIRE RUBBER CONCRETE}

\section{Marques, A. C. ${ }^{1}$, Nirschl, G. C. ${ }^{2}$; Akasaki, J. L. ${ }^{3}$}

\begin{abstract}
${ }^{1}$ Mestre em Engenharia Civil na área de Estruturas, Faculdade de Engenharia de Ilha Solteira, Universidade Estadual Paulista - UNESP, Ilha Solteira - S.P, cmarquesana@yahoo.com.br

${ }^{2}$ Aluno de Mestrado em Engenharia Civil na área de Estruturas, Escola de Engenharia de São Carlos, Universidade de São Paulo -USP - São Carlos - SP nirschl@bol.com.br

${ }^{3}$ Professor Doutor, Depto de Engenharia Civil, Faculdade de Engenharia de Ilha Solteira, Universidade Estadual Paulista - UNESP - Campus de Ilha Solteira Alameda Bahia, 550 - Centro - 15385-000 - Ilha Solteira - SP - Fone: (18) 37431213 akasaki@dec.feis.unesp.br
\end{abstract}

\section{RESUMO}

A disposição de resíduos provenientes de pneus fora de uso tem se tornado um problema para a maioria dos países. A proposta deste trabalho é proporcionar uma forma alternativa e limpa de reciclagem deste material prejudicial ao meio ambiente. $\mathrm{O}$ trabalho realizado tem como objetivo estudar o comportamento do concreto adicionado de resíduos de borracha de pneus; para isso, foram feitos vários traços com duas granulometrias diferentes e avaliadas propriedades como: resistência à compressão, resistência à tração, módulo de elasticidade, absorção de água e trabalhabilidade. Os ensaios foram feitos para as idades de 7, 28 e 56 dias em corposde-prova cilíndricos de dimensões $(10 \times 20) \mathrm{cm}$ e $(15 \times 30) \mathrm{cm}$ sendo o último utilizado apenas para o ensaio de módulo de elasticidade. Os resultados indicam redução nos valores referentes às propriedades mecânicas e perda na trabalhabilidade após a adição do resíduo.

Palavras Chave: Concreto com Borracha de Pneus, Propriedades Mecânicas, Materiais Alternativos. 


\begin{abstract}
The residues disposal from tire rubber out of use has become a problem for most of countries. This work proposal is to provide an alternative and clean way to recycle this material that is harmful for the environment. The work's aim is to study the behavior of tire rubber concrete through different mix proportions and two tire rubber aggregates gradation and evaluate properties as: compressive strength, splitting tensile test, modulus of elasticity, water absorption and workability. The tests were carried out to the ages of 7,28 and 56 days using cylindrical specimens of $(10 \times 20) \mathrm{cm}$ and $(15 \times 30) \mathrm{cm}$. The last specimens were used for modulus of elasticity tests. The results show that the addition of tire rubber in concrete reduces workability and mechanical properties values.
\end{abstract}

Key words: Tire Rubber Concrete, Mechanical Properties, Alternative Material.

\title{
1. INTRODUÇÃO
}

O aumento da produção de pneus assim como dos resíduos provenientes dos pneus fora de uso têm causado preocupações quanto à sua disposição final. E a quantidade de pneus produzidos tem aumentado a cada ano. De acordo com a ANIP (Associação Nacional da Indústria de Pneumáticos) foram produzidos no Brasil aproximadamente 45 milhões de pneus em 2001.

A preocupação com o meio ambiente pode ser observada nas providências tomadas por órgãos como o CONAMA (Conselho Nacional do Meio Ambiente), responsável pelas questões ambientais do país. Este estabeleceu regras para a destinação final de pneus fabricados no Brasil ou importados: a partir de $1^{\circ}$ de janeiro de 2005 para cada quatro pneus novos fabricados no País ou pneus novos importados, as empresas fabricantes e as importadoras deverão dar destinação final a cinco pneus inservíveis e para cada três pneus reformados importados, de qualquer tipo, as empresas importadoras deverão dar destinação final a quatro pneus inservíveis.

O uso deste resíduo em argamassa e concreto são formas alternativas limpas de reciclagem deste material, já que estes não devem ser colocados em aterros e sua queima libera gases tóxicos.

Portanto, visando o aproveitamento deste material em elementos da construção civil, vários pesquisadores fizeram estudos avaliando as propriedades de misturas adicionadas de borracha de pneus. Segundo a literatura, tanto em concreto quanto em argamassa a adição de resíduos de borracha de pneus atua de forma negativa para a resistência mecânica, seja ela à compressão, tração ou flexão. De acordo com Fattuhi (1996), Topçu (1995), Khatib e Bayomi (1999) e Eldin e Senouci (1992) também foi observado que o tamanho do resíduo e sua forma influenciam no resultado final. 
Entretanto, propriedades como isolamento térmico e acústico têm apresentado bom desempenho após a adição da borracha de pneus em argamassa (LIMA et al., 2000).

Outra propriedade também influenciada é a trabalhabilidade; pois de acordo com Khatib e Bayomi (1999) e Eldin e Senouci (1992), após a adição do resíduo nota-se diminuição da trabalhabilidade comparando as amostras referência com as adicionadas de borracha de pneus.

O objetivo deste trabalho é avaliar a influência da adição de resíduos de borracha de pneus em concretos submetidos a ensaios de resistência à compressão, resistência à tração, módulo de elasticidade, massa específica e abatimento do tronco de cone.

\section{MATERIAIS E MÉTODOS}

Os traços de concreto foram feitos com cimento Portland de alta resistência inicial CPV ARI PLUS, areia média agregado graúdo com diâmetro máximo de 19 $\mathrm{mm}$, água potável e borracha de pneus de automóveis proveniente da recauchutagem. As duas granulometrias da borracha utilizadas no trabalho, obtidas após peneiramento, foram: a granulometria 1 (denominada B), que vai de 0,8 a $2,38 \mathrm{~mm}$, e a granulometria 2 (denominada $\mathrm{BF}$ ), menor que $0,8 \mathrm{~mm}$, sendo que parte dos traços elaborados continha a granulometria $\mathrm{B}$ e parte a granulometria BF. A Tabela 1 apresenta a massa específica absoluta e aparente dos materiais utilizados no trabalho. Os resíduos utilizados podem ser vistos nas Figuras 1A e 1B.

Na Figura 2 é mostrada a curva granulométrica dos agregados utilizados no trabalho. A curva que representa a borracha de pneu mostra o material antes de ser separado, sendo utilizada apenas a parcela compreendida nas dimensões citadas anteriormente.

Tabela 1. Massa específica aparente e absoluta dos materiais utilizados no trabalho.

\begin{tabular}{|c|c|c|}
\hline Materiais & Massa unitária (kg/l) & Massa específica (kg/l) \\
\hline Cimento & 1,13 & 3,09 \\
\hline Areia & 1,5 & 2,75 \\
\hline Brita & 1,45 & 2,70 \\
\hline Borracha fina* & 0,27 & 1,09 \\
\hline Borracha grossa** & 0,27 & 1,09 \\
\hline
\end{tabular}

* resíduo que passa na peneira $\mathrm{n}^{\circ} 20$ da $\mathrm{ABNT}$

** resíduo que passa na peneira $n^{\circ} 8$ e fica retido na peneira $n^{\circ} 20$ da $A B N T$ 


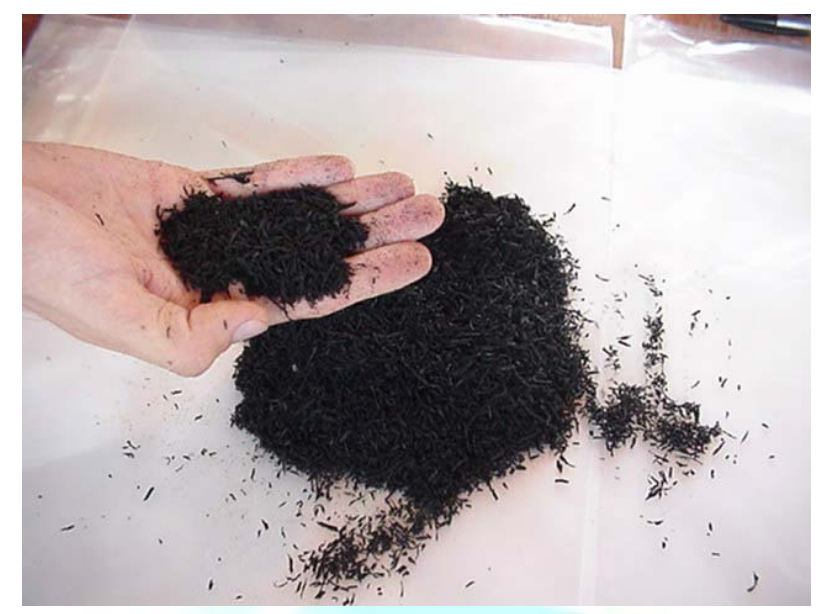

Figura 1A - Resíduos de borracha de pneu de 0,8-2,38mm (B)

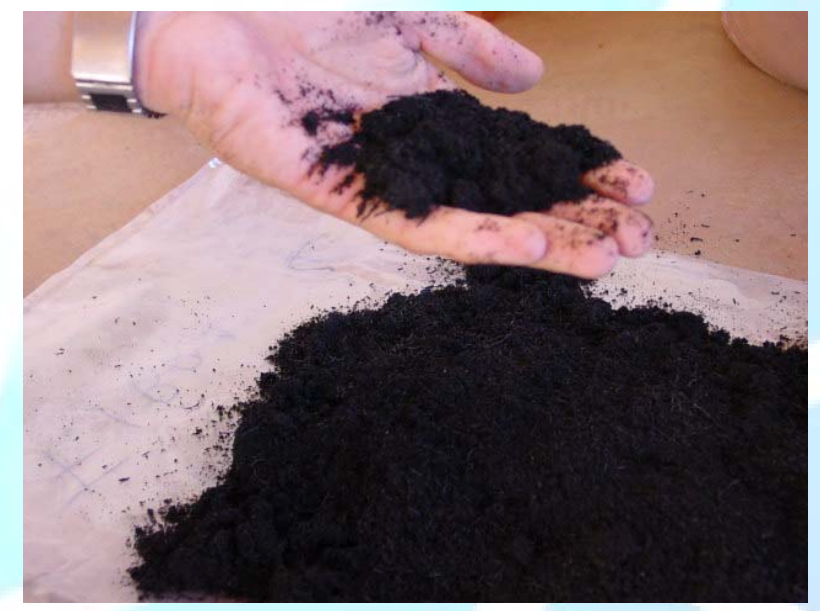

Figura 1B - Resíduos de borracha de pneus menores que de 0,8mm (BF)

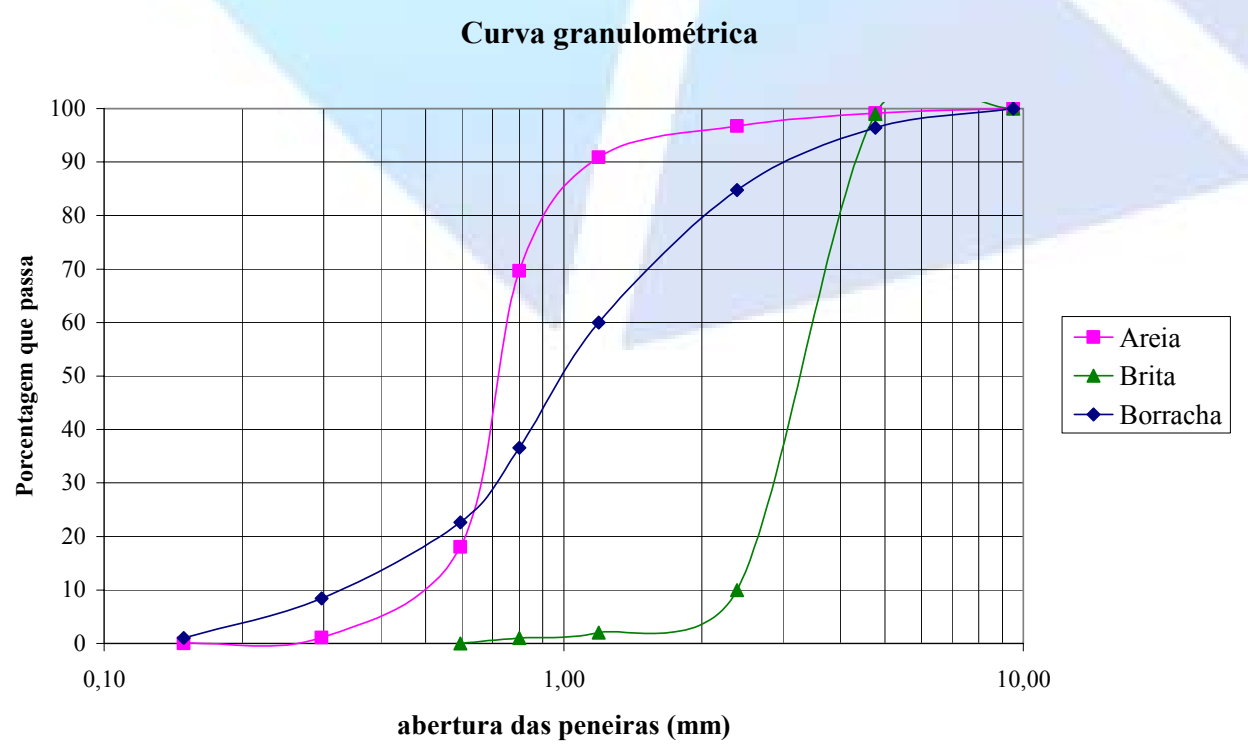

Figura 2 - Curva granulométrica dos agregados 
As proporções em massa utilizadas para confecção dos corpos-de-prova com e sem resíduos de borracha podem ser vistas na Tabela 2.

Tabela 2. Proporções de mistura para os traços com borracha e de referência

\begin{tabular}{|c|c|c|c|c|c|}
\hline \multirow{2}{*}{ Traço } & \multicolumn{5}{|c|}{ Consumo dos materiais em kg/m } \\
\cline { 2 - 6 } & Cimento & Água & Areia & Brita & Borracha \\
\hline Referência & 295,57 & 195,03 & 931,53 & $1.000,57$ & 0 \\
\hline B1 & 338,57 & 185,38 & 656,54 & $1.109,71$ & 77,42 \\
\hline B2 & 348,51 & 182,44 & 528,61 & $1.166,92$ & 112,50 \\
\hline B3 & 344,30 & 180,24 & 487,80 & $1.152,83$ & 145,58 \\
\hline B4 & 336,37 & 176,09 & 464,81 & $1.126,29$ & 180,44 \\
\hline BF2 & 347,47 & 181,90 & 527,04 & $1.163,45$ & 112,17 \\
\hline BF3 & 337,17 & 192,66 & 478,25 & $1.130,15$ & 142,76 \\
\hline
\end{tabular}

A partir do traço referência, foi feita a substituição em volume de parte do agregado miúdo por borracha de pneu. As misturas B1, B2, B3 e B4 são as que contêm o resíduo de borracha de maior granulometria e apresentam percentagem em volume de borracha de $15 \%, 20 \%, 25 \%$ e $30 \%$, enquanto as misturas BF2 e BF3 são constituídas pelos resíduos de borracha de menores dimensões, apresentando quantidades de 20 e $25 \%$ em volume de borracha.

Após a moldagem, os corpos-de-prova foram colocados em câmara úmida permanecendo no local até a data de ensaio. Foram estudadas propriedades tanto no estado fresco quanto no endurecido. A trabalhabilidade foi avaliada através do ensaio de abatimento de cone. Os ensaios realizados no estado endurecido foram feitos segundo a Associação Brasileira de Normas Técnicas (ABNT). Os ensaios realizados foram: resistência à compressão, resistência à tração por compressão diametral e módulo de elasticidade, respectivamente de acordo com a ABNT (1994a), ABNT (1994b) e ABNT (1994c), para as idades de 7, 28 e 56 dias. Além dos ensaios citados anteriormente também foi feita a determinação de massa específica. Foram usados três corpos-de-prova por idade, de dimensões $(10 \times 20) \mathrm{cm}$, com exceção do módulo de elasticidade que utilizou corpos-de-prova de $(15 \times 30) \mathrm{cm}$.

\section{RESULTADOS E DISCUSSÃO}

\section{Trabalhabilidade}

A avaliação da trabalhabilidade, determinada através do ensaio de abatimento do tronco de cone, pode ser observada na Tabela 3. 
Tabela 3. Abatimento do tronco de cone

\begin{tabular}{|c|c|}
\hline Traço & Abatimento em cm \\
\hline Controle & 6,0 \\
\hline B1 & 2,7 \\
\hline B2 & 1,2 \\
\hline B3 & 1,0 \\
\hline B4 & 0 \\
\hline BF2 & 2,0 \\
\hline BF3 & 0 \\
\hline
\end{tabular}

A relação água cimento dos concretos acrescidos de borracha manteve-se ligeiramente constante (da ordem de 0,50 ), sendo menor que a do traço controle (C $\mathrm{A} / \mathrm{C}$ de 0,66$)$. Pois, a substituição de parte do agregado miúdo em volume por borracha de pneu, altera sua composição e, portanto, o consumo de cimento. Isto se refletiu na trabalhabilidade dos concretos, pois como pode ser visto, pela Tabela 3, a quantidade de borracha adicionada ao concreto, assim como a sua granulometria interferem em sua trabalhabilidade.

Comparações feitas entre os traços B1, B2, B3 e B4 mostram que, quanto maior a quantidade de borracha adicionada à mistura, menor o abatimento. Também foi observado que os traços contendo a borracha de granulometria mais fina apresentam melhor trabalhabilidade que os com granulometrias mais grossas. Isto pode ser observado pela comparação entre os traços B2 e BF2, que apresentam substituição de $20 \%$ em volume do agregado por borracha de pneu.

\section{Resistência à compressão}

A Figura 3 apresenta os resultados de resistência à compressão para as idades de 7,28 e 56 dias.

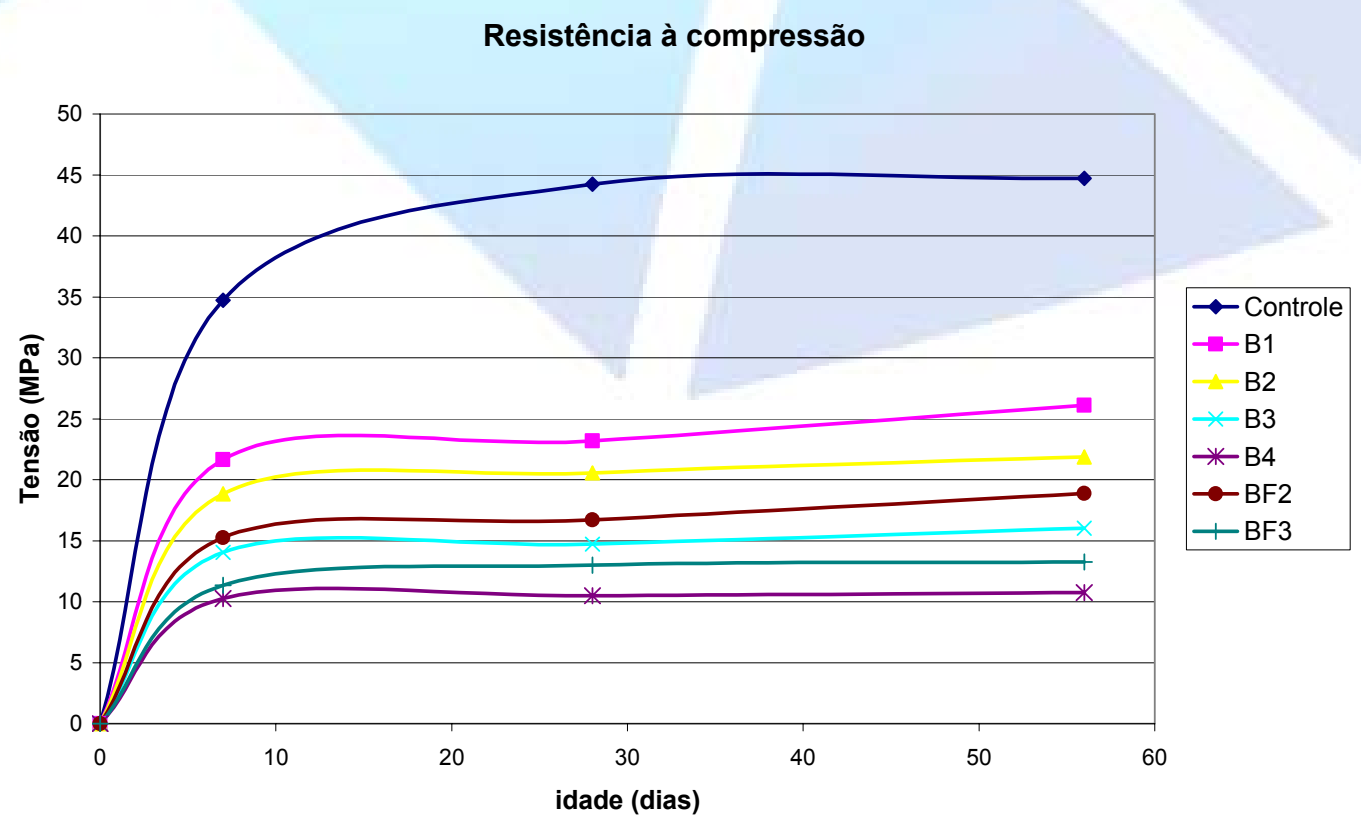

Figura 3. Resistência à compressão dos corpos-de-prova 
O consumo de cimento dos traços B1, B2, B3 e B4 mantiveram uma ordem de grandeza acima de $330 \mathrm{~kg} / \mathrm{m}^{3}$ de concreto, enquanto que o traço Referência esteve abaixo de $300 \mathrm{~kg} / \mathrm{m}^{3}$ de concreto.

Verifica-se, através da Figura 3, que a adição da borracha de pneus ao concreto provoca queda na resistência à compressão, isso pode ser visto através da comparação da curva referência com as curvas obtidas pelo ensaio no concreto com borracha de pneus. Mesmo apresentando um consumo menor de cimento, o concreto referência obteve resultados maiores que o concreto com borracha de pneu. Isto pode ser atribuído à falta de aderência entre a pasta e o resíduo de borracha e também à substituição de um agregado por outro de menor resistência e maior deformabilidade. Entre os concretos adicionados de resíduo, o que melhor resistiu à compressão foi o B1 (23,17 MPa aos 28 dias). Não por acaso, é a composição que contém menos borracha $(14,61 \%$ em volume $)$.

\section{Resistência à tração}

Os resultados obtidos para o ensaio de resistência à tração por compressão diametral para os corpos-de-prova controle e os adicionados de borracha podem ser vistos na Figura 4.

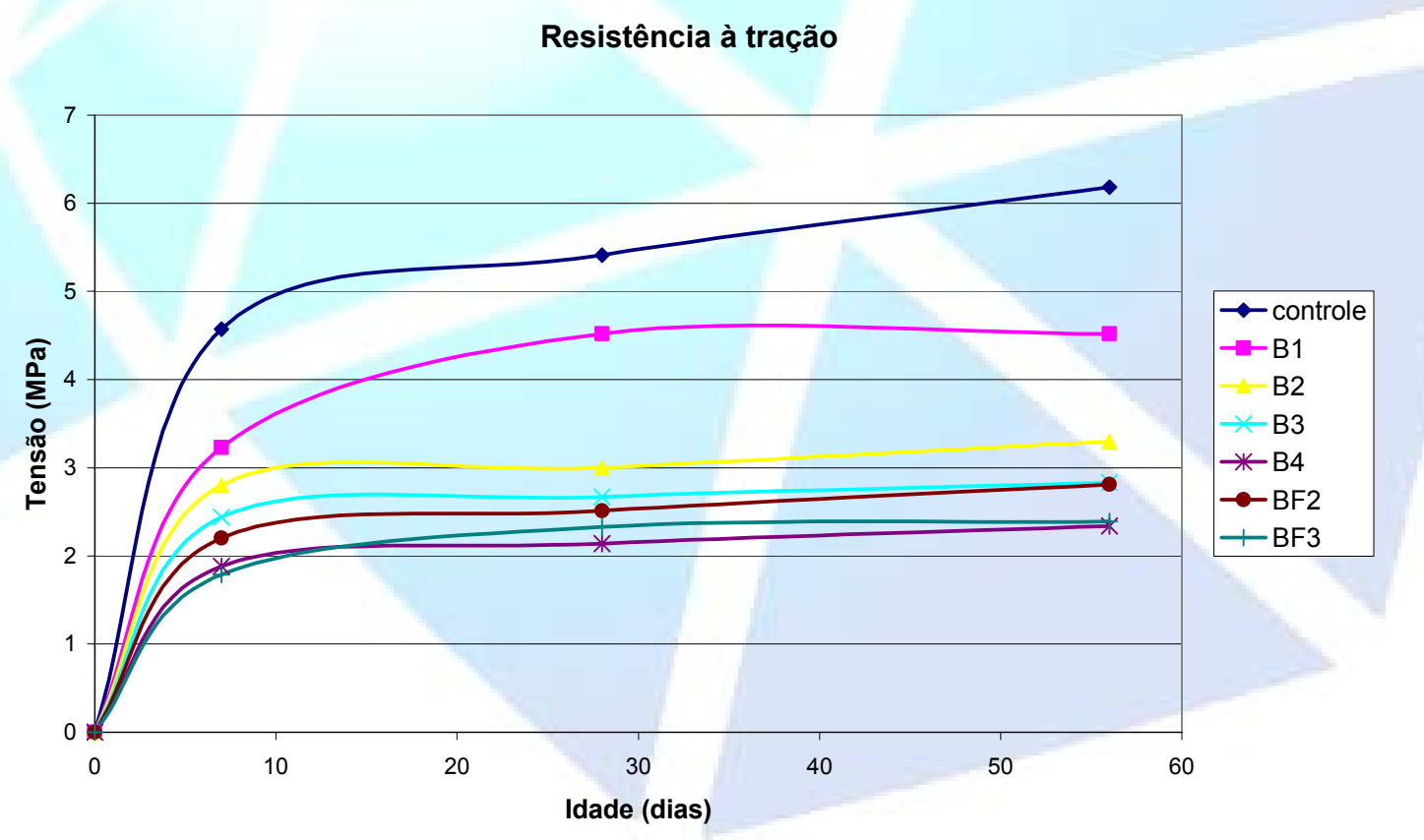

Figura 4. Resistência à tração

Nos resultados de resistência à tração, assim como nos de resistência à compressão, observa-se decréscimo nos valores comparando as misturas contendo borracha com a mistura referência. Aos 56 dias houve perda de 27\%, 47\%, 54\%, $62 \%, 54 \%$ e $61 \%$ da resistência à tração respectivamente para B1, B2, B3, B4, BF2 e $\mathrm{BF} 3$, quando comparadas ao concreto usado como referência. 


\section{Módulo de elasticidade}

Como a resistência à compressão e o módulo de elasticidade são duas propriedades diretamente ligadas, os resultados de módulo de elasticidade acompanharam o comportamento da resistência à compressão, como pode ser visto na Figura 5. Percebe-se também, na Figura 5 que os resultados de módulo de elasticidade dos concretos contendo borracha foram menores do que os do concreto convencional, o que fora esperado devido a deformabilidade da borracha.

\section{Módulo de elasticidade}

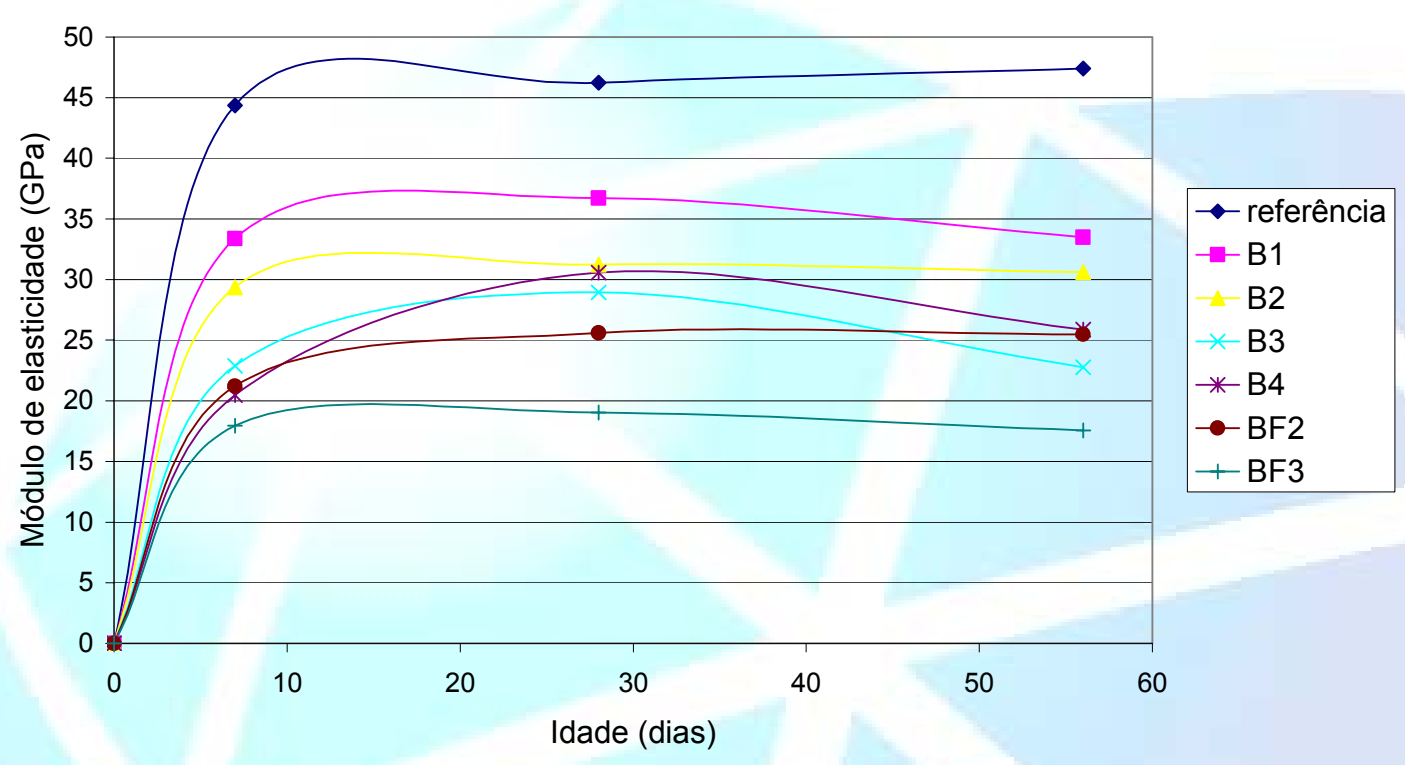

Figura 5. Módulo de elasticidade

Fazendo-se uma análise da Figura 5, pode-se notar que a composição com borracha mais grossa (Traço B2) apresenta maiores valores de módulo de elasticidade do que a mistura com borracha mais fina (Traço BF2, com composição semelhante em termos de \% de volume).

\section{Massa específica unitária}

A quantidade de borracha adicionada ao concreto também influi em sua massa unitária; visto que um agregado mais leve substitui o agregado natural. As substituições foram feitas apenas no agregado miúdo e a determinação da massa unitária foi feita para a idade de 28 dias. O comportamento dos traços com e sem borracha pode ser visto na Figura 6. 


\begin{tabular}{|l|r|}
\hline Recebido em: $27 / 04 / 2005$ & HOLOS Environment, v.6 n.1, 2006 - P. 39 \\
\hline Liberado para Publicação em: $21 / 06 / 2006$ & ISSN: 1519-8634 \\
\hline
\end{tabular}

\section{Massa unitária}

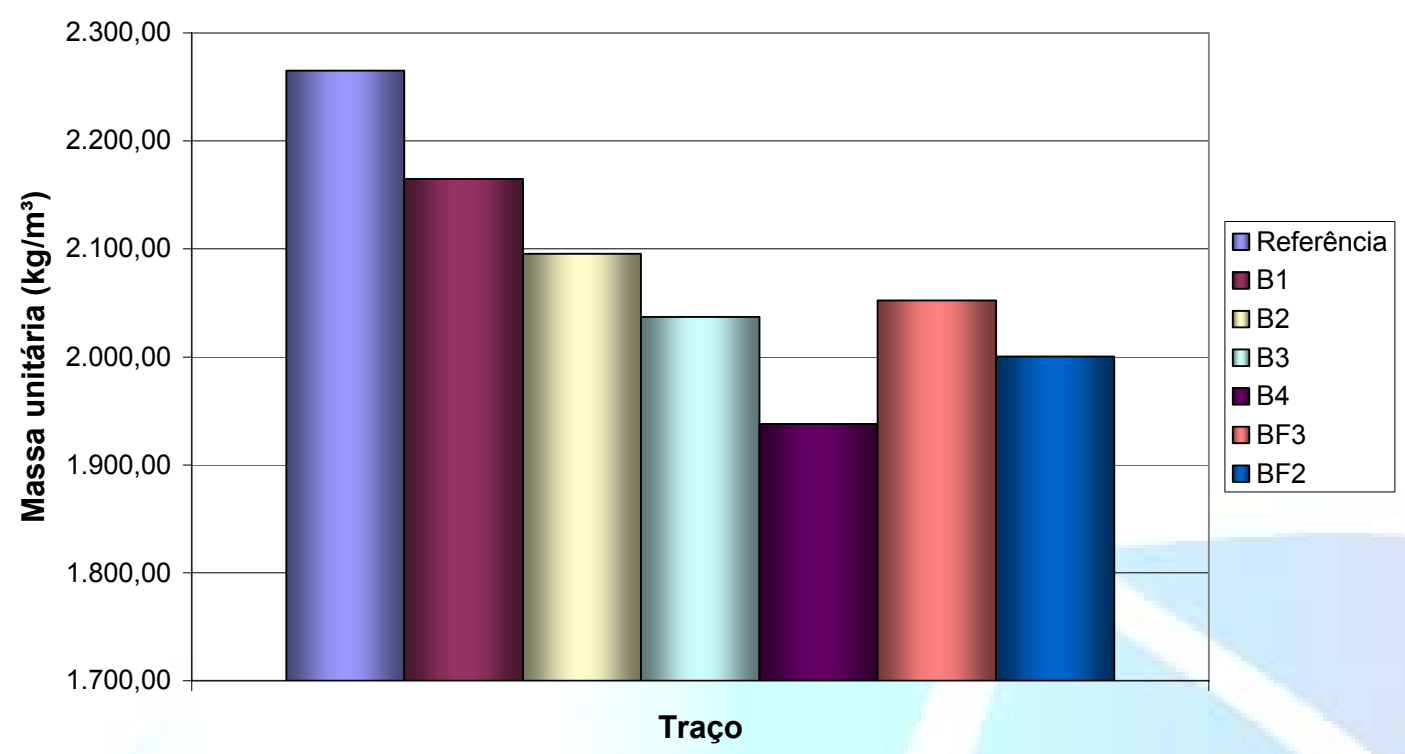

Figura 6 - Massa unitária

Pode-se ver na Figura 6 que quanto maior a quantidade de borracha adicionada mais leve a mistura se torna. Enquanto o concreto Referência (Traço C) apresentou $2.265 \mathrm{~kg} / \mathrm{m}^{3}$ de massa unitária seca, os concretos com resíduo têm de $1.937 \mathrm{~kg} / \mathrm{m}^{3}$ (traço B4) até $2.164 \mathrm{~kg} / \mathrm{m}^{3}$ (traço B1) de massa unitária seca, ou seja, uma redução de 4,6 a $16,9 \%$ na massa unitária. Também pode ser visto que a granulometria utilizada não influencia nos resultados visto que a diferença entre os resultados com corpos-deprova contendo a mesma quantidade de borracha foi da ordem de $2 \%$.

\section{CONCLUSÕES}

Pode-se concluir destes estudos que, em função da trabalhabilidade e resistência, o valor limite de adição de borracha em concreto estaria entre $25 \%$ e $30 \%$ em relação ao volume total de materiais. Isto pode ser representado pelo traço B4 (30,14\% de borracha em volume), o qual apresentou resultados mais baixos de resistência à compressão e não conseguiu uma boa trabalhabilidade, dificultando a moldagem dos corpos-de-prova.

Percebe-se que, apesar de os Traços de concreto com adição de borracha apresentarem relações água/cimento inferiores ao do Traço referência, os resultados dos ensaios de resistência mecânica apresentaram valores menores.

Ressalta-se que há, no mercado, vários tipos de resíduos de borracha provenientes da recauchutagem e da reciclagem de pneus, sendo necessário fazer estudos abrangendo resíduos de outras procedências. 
Além disso, na presente pesquisa foram ensaiados traços de concreto com apenas duas faixas granulométricas de resíduo. Deve-se procurar, no entanto, uma granulometria ótima a ser incorporada, já que há divergência entre artigos até o momento publicados. Alguns autores revelaram melhoria no desempenho mecânico e na trabalhabilidade devido ao uso de fibras mais finas, sendo observado nesta pesquisa o contrário ou a não influência da granulometria.

Finalmente, há muito que se investigar acerca da incorporação de aditivos e superplastificantes no concreto com borracha de pneus. Deve-se fazer estudos mais elaborados, utilizando-se uma ampla variedade de aditivos.

Mesmo quando todos os problemas de trabalhabilidade, custos e parâmetros de resistências do concreto com borracha forem resolvidos, haverá um problema talvez ainda mais complexo, a durabilidade, que exigirá mais tempo de investigações. Encaixam-se neste tópico a resistência ao fogo, isolamento térmico e acústico, formação de fissuras, ataques químicos, aderência com a armadura e muitos outros.

Portanto, há muito que se aperfeiçoar nos estudos deste tipo de concreto, mas esta pesquisa dá indícios de que o concreto com borracha de pneus pode substituir o uso do concreto convencional em situações de média exigência de resistência, a princípio, com o nobre objetivo ecológico de aproveitamento deste resíduo tão prejudicial à natureza.

\section{AGRADECIMENTOS}

Os autores agradecem à FAPESP (Fundação de Amparo à Pesquisa do Estado de São Paulo) pelo apoio financeiro, Holcim Brasil, empresa responsável pela doação do cimento utilizado no trabalho, Araçá - Recauchutadora de pneus, por fornecer o resíduo de borracha de pneu e LCEC (Laboratório CESP de Engenharia Civil), por permitir o uso do laboratório tanto para moldagem quanto para a realização dos ensaios.

\section{REFERÊNCIAS}

ASSOCIAÇÃO BRASILEIRA DE NORMAS TÉCNICAS. NBR 5739 - Concreto Ensaio de compressão de corpos-de-prova cilíndricos. Rio de Janeiro, 1994a.

ASSOCIAÇÃO BRASILEIRA DE NORMAS TÉCNICAS. NBR 7222 - Argamassa e concreto - Determinação da resistência à tração por compressão diametral de corpos-de-prova cilíndricos. Rio de Janeiro, 1994b. 
ASSOCIAÇÃO BRASILEIRA DE NORMAS TÉCNICAS. NBR 8522 - Concreto Determinação do módulo de deformação estática $e$ diagrama tensãodeformação. Rio de Janeiro, 1994c.

ELDIN, N. N., SENOUCE, A. B. Rubber-tyre particles as concrete aggregate. Journal of Materials in Civil Engineering, v 5, nº 4, p.74-84, 1992.

FATTUHI, N. L., CLARK L. A. Cement-based materials containing shredded scrap truck tire rubber. Construction and Building Materials, v 10, p. 223-236, 1996.

KHATIB, Z. K., BAYOMY, F. M. Rubberized Portland Cement Concrete. Journal of Materials in Civil Engineering, v 11, nº 3, p. 206-213, 1999.

LIMA, I. S., ROCHA, F. S., FERREIRA, J. B. Um Estudo de Argamassa de Cimento com Adição de Fibras de Borracha Vulcanizada para a Construção Civil. $42^{\circ}$ Congresso Brasileiro do Concreto, 2000, Fortaleza. IBRACON, 2000.

TOPÇU, I., B. The properties of rubberized concretes. Cement and Concrete Research. v.25, nº 2, p.304-310, 1995. 